\title{
Histopathology
}

\section{Expression of heat shock proteins in classical Hodgkin lymphoma: correlation with apoptotic pathways and prognostic significance}

\begin{tabular}{|c|c|}
\hline Journal: & Histopathology \\
\hline Manuscript ID: & HISTOP-08-10-0432 \\
\hline Wiley - Manuscript type: & Original Article \\
\hline $\begin{array}{r}\text { Date Submitted by the } \\
\text { Author: }\end{array}$ & 09-Aug-2010 \\
\hline Complete List of Authors: & $\begin{array}{l}\text { Santón, Almudena; Hospital Ramon y Cajal, Pathology } \\
\text { Garcia-Cosio, Monica; Hospital Ramon y Cajal, Pathology } \\
\text { Cristobal, Eva; Hospital Ramon y Cajal, Pathology } \\
\text { Pascual, Alejandro; Hospital Ramon y Cajal, Pathology } \\
\text { Muriel, Alfonso; Hospital Ramon y Cajal, Biostatistics } \\
\text { García-Laraña, José; Hospital Ramon y Cajal, Haematology }\end{array}$ \\
\hline Keywords: & caspases, heat shock proteins, Hodgkin lymphoma \\
\hline
\end{tabular}

\section{SCHOLARONE Manuscripts}


A. Santón et al.

Title Page

\section{Expression of heat shock proteins in classical Hodgkin lymphoma:}

\section{correlation with apoptotic pathways and prognostic significance}

Almudena Santón, ${ }^{1}$ Mónica García-Cosío, ${ }^{1}$ Eva Cristóbal, ${ }^{1}$ Alejandro Pascual, ${ }^{1}$ Alfonso Muriel, ${ }^{2}$ and José García-Laraña ${ }^{3}$

${ }^{1}$ Department of Pathology, Ramón y Cajal University Hospital, IRYCIS, Madrid, Spain; ${ }^{2}$ Biostatistics Unit, Ramón y Cajal University Hospital, IRYCIS, Red CIBERESP, Madrid, Spain; and ${ }^{3}$ Department of Haematology, Ramón y Cajal University Hospital, IRYCIS, Madrid, Spain

Correspondence, proofs, and reprint requests to:

Almudena Santón, Department of Pathology, University Hospital Ramón y Cajal, Carretera de Colmenar Km. 9.100, 28034 Madrid, Spain. Phone number: +34913368278. Fax number: +34913369016. E-mail: asanton.hrc@salud.madrid.org

\section{Running title}

Heat shock proteins in Hodgkin lymphoma

Key words: caspases, heat shock proteins, Hodgkin lymphoma 


\title{
A. Santón et al.
}

\begin{abstract}
Aims: Heat shock proteins (HSPs), which are known to inhibit apoptosis and promote cellular survival, are over-expressed in many tumours. We analyzed the expression of relevant HSPs and heat shock factor 1 (HSF1) in classical Hodgkin lymphoma (cHL) and their relationship with caspase signalling pathways and patient outcome.
\end{abstract}

Methods and results: Using tissue-microarrays, most cases showed strong immunohistochemical expression of HSPs $(10,27,40,60,70,90,110, \mathrm{HO} 1, \mathrm{CDC} 37)$ and HSF1, which points to $\mathrm{cHL}$ as a potential candidate to stress-response inhibitors. Active caspases 3, 8, and 9 were detected in $55.1 \%, 55.4 \%$, and $96.2 \%$ of cases; however, cleaved PARP was observed only in $16.1 \%$, suggesting improper functioning of apoptosis. Statistical analysis showed associations of HSP70 with active caspase $3(\mathrm{p}=0.000)$; HSP40 with active caspase $9(\mathrm{p}=0.031)$ and p53 (p=0.003); HO1 with p53 (p=0.006) and p21 (p=0.005); and p53 with p21 $(\mathrm{p}=0.015)$.

Conclusions: Correlations between the expression of apoptotic markers and HSPs may suggest a role for the latter in modulating apoptosis in cHL, mainly through the HSP70HSP40 system, and in the stabilization of p53. Survival analyses showed that absence of active caspase 8 and $\mathrm{HO} 1$ had a negative impact in patient outcome. 


\section{A. Santón et al.}

\section{Introduction}

Classical Hodgkin lymphoma (cHL) is characterized by the presence of scarce neoplastic Hodgkin/Reed-Sternberg (HRS) cells in a background of reactive cells. HRS cells are clonal germinal center-derived B cells with rearranged and somatically mutated but nonproductive immunoglobulin genes that escape from CD95-mediated apoptosis. ${ }^{1}$ The antiapoptotic phenotype of HRS cells has been mainly atributed to constitutive NF-kB activation, and is mediated by several molecules including c-FLIP and XIAP. ${ }^{2-4}$ The dysregulation of apoptosis is a key feature of lymphoma pathogenesis and many therapeutic approaches are focused on neutralizing mediators of the antiapoptotic and pro-proliferative phenotype of tumour cells. Promising targets for anti-cancer drug design are heat shock proteins (HSPs) due to their cytoprotective function.

HSPs are highly conserved proteins which besides functioning as molecular chaperones play a pivotal role in apoptosis inhibition and cell survival. HSPs are classified into 5 groups according to their molecular size: HSP100, HSP90, HSP70, HSP60, and small HSPs. ${ }^{5}$ Under the control of the heat-shock factor 1 (HSF1), which is the major regulator of cellular response to stress, HSPs are rapidly induced in response to different damaging stimuli. The cytoprotective function of HSPs reflects their ability to suppress the apoptotic signalling pathway at multiple points. For instance, at the pre-mitochondrial stage HSPs regulate prosurvival signalling cascades mediated by AKT, JNK, and NF-kB; at the mitochondrial level inhibit the mitochondrial outer membrane permeabilization and the release of pro-apoptotic proteins and, finally, at the post-mitochondrial level, prevent caspase activation. 6,7

In normal, non-stressed cells inducible HSPs are poorly expressed; in contrast, overexpression of HSPs has been reported in many tumours and in some types this is linked with worse prognosis and chemo-resistance. Although pharmacological blockade of HSPs is an 
A. Santón et al.

attractive strategy for cancer treatment, up to now only inhibitors of HSP90 have been clinically tested. $8-10$

Little is known about the expression of HSPs in cHL and the role that HSPs may play in the establishment and maintenance of the malignant HRS phenotype. Abundant expression of HSP90 and HSP60, and lower levels of HSP27 have been described in a small group of HL cases using immunohistochemical (IHC) methods; 11 however, the IHC expression profile of HSF1 and most HSPs, as well as the possible prognostic significance of such expression are not established in cHL.

Using tissue microarrays, we analyzed the IHC expression of HSP families and HSF1 in HRS cells of cHL and their relationship with different markers for the status of the extrinsic and intrinsic apoptotic pathways and with patient outcome.

\section{Materials and Methods}

This work was approved by the Ethics Committee of our institution.

\section{PATIENTS AND TISSUE SAMPLES}

Diagnostic biopsy samples from a total of 89 patients with cHL were retrospectively collected from the files of the Pathology Department of Ramón y Cajal Hospital during the period between 1989 and 2002.

Complete clinical, analytical, therapeutical, and follow-up data were available from 76 of them. Data recorded in the database included: sex, age, Ann Arbor stage, presence of B symptoms, histological type, number of lymph nodes and extranodal sites, analytic variables included in the international prognostic score (IPS), response to therapy (complete response versus treatment failure), disease free survival (DFS) from the achievement of complete remission until relapse, death or last follow-up, and overall survival (OS) from the time of 


\section{A. Santón et al.}

diagnosis to last follow-up or death. Complete remission (CR) was defined as the absence of clinical and radiological evidence of disease for a minimum period of 4 weeks.

All patients were treated with standard polychemotherapeutic regimens (adriamycincontaining regimens or MOPP regimens) with or without adjuvant radiotherapy. Some patients with refractory disease also received autologous peripheral stem-cell transplantation. The histological confirmation of cHL was made in pre-treatment standard tissue sections from lymph node biopsies in 86 cases and from an extranodal site in 3 cases, using H\&E, CD20, CD3, CD30, CD15 and PAX5 staining, and according to the World Health Organization (WHO) classification. There were 51 nodular sclerosis, 24 mixed cellularity, 10 lymphocyterich, 2 lymphocyte depletion and 2 unclassifiable HL.

Reactive lymphoid tissue and different B- and T-cell lymphoma samples were also collected from the tissue archive.

\section{TISSUE MICROARRAY DESIGN}

A Tissue Arrayer device (Beecher Instrument, Silver Spring, MD, USA), kindly provided by Centro Nacional de Investigaciones Oncológicas, was used to construct the tissue microarrays (TMA). The suitability of TMA for the study of HL has been proved elsewhere. ${ }^{12}$ Paraffin blocks were selected only on the basis of the availability of formalin-fixed, paraffinembedded tissue (at least $1 \mathrm{~mm}$ thick). Two different TMA blocks were constructed, each containing duplicate cores from the areas richest in neoplastic cells of the selected $89 \mathrm{cHL}$ cases. Abundant tumour cells had to be identified in the two cylinders for a case to be recorded in the study.

Cylinders of external controls were also included in the TMA blocks and consisted on a representation of reactive lymphoid tissue (2 tonsils and 3 reactive lymphadenitis) and different samples of non-Hodgkin lymphomas (2 diffuse large B-cell lymphoma and 2 peripheral T-cell lymphoma, NOS), all of them collected from the archive. 


\section{A. Santón et al.}

IHC staining was performed on the TMA sections following previously described methods. 12,13 Twenty different antibodies were used whose source, dilution and pattern of positivity are listed in Table 1.

Antibodies were incubated overnight at $4^{\circ} \mathrm{C}$ or 30 minutes at room temperature (HSPs 10, 27, 60, 90, and 110, CDC37, BCL2, p53 and p21); immunodetection was subsequently performed with the ENVISION DUAL LINK Visualization System (DAKO, Glostrup, Denmark).

Immunodetection of HSP70 and HSP40 was accomplished incubating 30 minutes at room temperature with a peroxidase-conjugated rabbit anti-rat (HSP70) or anti-goat (HSP40) secondary antibody at 1/100 dilution (Jackson ImmunoResearch, West Grove, PA, USA).

Internal controls were provided in each case by the reactivity of the accompanying lymphocytes, plasma cells, macrophages or endothelial cells.

The staining of the TMA sections for the different antibodies was independently evaluated by two pathologists (M.G-C. and A.P.) according to previously published criteria. 3, 4, 12-15 Concurrent results in the two cores were essential to be considered suitable for the study.

For HSF1 and HSPs, samples were considered positive if $10 \%$ of more of the malignant cells expressed the corresponding protein as least as intense as reactive accompanying cells. Although an arbitrary $10 \%$ cut-off was established, in positive samples these proteins were strongly expressed virtually by all tumour cells with relatively lower levels by the reactive cells.

Epstein-Barr virus (EBV) was detected by in situ hybridization with FITC-conjugated EBER probes (DAKO) on tissue microarray sections as previously described. ${ }^{13}$ The pattern of nuclear staining was recorded in HRS cells as: +, positivity in most cells; -, completely absent. The positivity in bystander lymphocytes was not recorded.

STATISTICAL ANALYSIS 


\section{A. Santón et al.}

The relationships between the expression of the different markers included in the study were analyzed by Pearson chi-square test and Fisher exact test.

A univariate analysis was performed for each clinical variable and for the tumour expression of the analyzed markers. Actuarial survival curves in terms of OS and DFS were constructed according to the Kaplan-Meier method. Comparison of the survival curves for each variable was performed using the log-rank test and Cox univariate analysis.

A backward multivariate analysis was performed using the Cox proportional hazards model to identify factors that might be of independent significance in influencing OS and DFS. The maximal model was formed by the variables found significant in the univariate analysis. Proportional hazard assumption was assessed by Schoendfeld residual.

All values were based on 2-tailed statistical analysis, with values of $\mathrm{p}<0.05$ considered statistically significant. The statistical analyses were performed using the SPSS statistical software package (SPSS Inc, Chicago, IL).

\section{Results}

\section{CLINICAL FINDINGS}

Briefly, $57.5 \%$ of patients were males and $42.5 \%$ were females. The range of age at diagnosis varied between 7 and 83 years, with a median of 47 years. At diagnosis, most patients presented with stage II (44.4\%) and had low IPS (0 to $2,77.5 \%)$. B symptoms were present in 49.4\% of cases. Most patients were treated with conventional chemotherapeutic regimens containing adryamicin $(85.5 \%)$ with or without radiotherapy. Two patients $(2.6 \%)$ presenting with low-stage disease were treated only with excisional surgery and $3(3.9 \%)$ received only radiotherapy. Seven patients $(9.1 \%)$ in advanced-stage received autologous peripheral stemcell transplantation either as consolidation therapy or as escalating treatment after partial response. CR was achieved by 67 patients $(88.2 \%)$ and 25 (32.9\%) experienced relapse. The median follow-up was 89 months. The clinical data of the patients are summarized in Table 2. 
A. Santón et al. IMMUNOHISTOCHEMISTRY AND IN SITU HYBRIDIZATION ANALYSES FOR EBV

The IHC evaluation of the different markers tested in the TMAs showed that almost all cHL cases displayed in HRS cells strong expression of HSF1 (98.7\%), HSP60 (100\%), HSP90 (89.3), HSP110 (98.7\%), HO1 (96.3\%), HSP10 (100\%), and CDC37 (92.4\%) (Figure 1). The frequency of cases showing positive staining for the remaining HSPs was lower: $55.4 \%$ for HSP27, 78.6\% for HSP70, and 78.2\% for HSP40. As expected, correlation was found between the expression of HSP60, HSP70 and HSP90, and their corresponding co-chaperones HSP10, HSP40 and CDC37, respectively ( $p=0.000)$.

EBV was detected by EBER in situ hybridization in the neoplastic HRS cells in $50.6 \%$ of cHL cases (42 of 83); however, its presence was not associated with any histological subtype. Although EBERs have been shown to up-regulate BCL2 and to increase resistance to apoptosis, we did not find any relationship between EBER expression and BCL2, c-FLIP, XIAP, p53 or p21.

Active caspases 3, 8, and 9 were detected in $55.1 \%, 55.4 \%$, and $96.2 \%$ of cases, respectively. Despite the detection of active caspase 3 in approximately half of the samples, cleaved PARP (the main product of caspase 3 proteolytic activity) was observed only in $16.1 \%$ of cases.

Apoptosis inhibitors BCL2, XIAP, and c-FLIP were expressed in 57.8\%, 73.4\%, and 66.7\% of biopsies, respectively. The phosphorylated form of the pro-survival protein AKT was present in $97.4 \%$ of cases.

P53 was expressed in $89.5 \%$ of patients and p21 in $96.25 \%$; a significant association between both markers was found $(\mathrm{p}=0.015)$.

Statistical analysis showed direct significant associations of HO1 with p53 $(\mathrm{p}=0.006)$ and p21 $(\mathrm{p}=0.005)$; HSP40 with $\mathrm{p} 53(\mathrm{p}=0.003)$, active caspase $9(\mathrm{p}=0.031)$ and c-FLIP $(\mathrm{p}=0.036)$; and HSP70 with active caspase $3(\mathrm{p}=0.000)$.

SURVIVAL ANALYSIS 


\section{A. Santón et al.}

The study was performed in 76 patients from the initial 89 for which adequate clinical and laboratory data from the time of diagnosis, as well as follow-up information were available.

Consistent with previous studies, advanced stage at presentation $(\geq 3)$ and age 45 years or more were strong prognostic markers associated with worse OS $(p=0.001$ and $p=0.006$, respectively). Stage 3 or 4 also associated with shorter DFS $(\mathrm{p}=0.043)$.

OS was significantly longer in patients expressing HO1 (Hazard Ratio $(\mathrm{HR})=0.172, \mathrm{p}=$ 0.005); p53 $(\mathrm{HR}=0.298, \mathrm{p}=0.010) ; \mathrm{p} 21(\mathrm{HR}=0.250, \mathrm{p}=0.025)$; active caspase $8(\mathrm{HR}=0.413$, $\mathrm{p}=0.039)$; active caspase $9(\mathrm{HR}=0.224, \mathrm{p}=0.049)$ and $\mathrm{p}$-AKT $(\mathrm{HR}=0.061, \mathrm{p}=0.001)$. Longer DFS was associated with HSP27-negative status $(\mathrm{p}=0.014)$.

In order to identify independent predictors for OS and DFS, a multivariate analysis was performed including in the model the variables found significant in the univariate analysis. Advanced stage at presentation $(\mathrm{HR}=11.89 ; \mathrm{p}=0.000)$, lack of active caspase $8(\mathrm{HR}=4.67, \mathrm{p}=$ 0.001) and absence of $\mathrm{HO} 1$ expression $(\mathrm{HR}=20.83, \mathrm{p}=0.001)$ remained as independent adverse prognostic factors for OS (Figure 2). To compensate for the heterogeneity in treatment regimens of our series, multivariate analysis was subsequently performed taking into account only the patients treated with adriamycin-containing regimens. This analysis showed that the three former variables: advanced stage at presentation $(H R=16.605, p=$ $0.000)$, lack of active caspase $8(\mathrm{HR}=8.197, \mathrm{p}=0.000)$ and absence of HO1 expression $(\mathrm{HR}=62.5, \mathrm{p}=0.000)$ hold and even improved their significance. The relevance of HO1 as a prognostic marker is only indicative and must be taken with caution since few negative cases were identified. IHC staining showed that in these cases HO1 expression was completely absent from all neoplastic cells.

For DFS, only advanced stage at diagnosis appeared as independent predictor of poor outcome $(\mathrm{HR}=2.406, \mathrm{p}=0.043)$.

\section{Discussion}




\section{A. Santón et al.}

Despite great clinical progress in the treatment of $\mathrm{cHL}$, current therapeutic regimens have long-term adverse effects. 16 In this setting, the identification of accurate prognostic factors and the development of non-genotoxic therapeutic agents are major goals in the management of cHL. HSPs are promising targets for the treatment of cancer because the inhibition of HSP function allows the simultaneous modulation of multiple client proteins involved in growth control and cell survival.9, 10

Over-expression of HSPs relative to normal tissues is a common feature of human cancers and is associated with poor prognosis and resistance to therapy. ${ }^{17-19}$ However, few data are available regarding the expression of HSPs in cHL and their correlation with prognosis. In an early work, abundance of HSP90, HSP60 and HSP27 was described in HRS cells in a group of 25 HL cases. ${ }^{11}$ More recently, strong IHC expression of HSP90 was reported in 35 out of $37(95 \%)$ cHL patients. ${ }^{20}$ In the present study, we confirm that main HSPs $(27,60,70,90$, 110 and HO1) and co-chaperones (CDC37, HSP10 and HSP40) are strongly expressed in HRS cells, so too is the major transactivator of HSP induction, HSF1. This finding is of interest since it points to $\mathrm{cHL}$ as a possible candidate to stress-response inhibitors. To date, only HSP90 small-molecule inhibitors have been available to be clinically tested. 21 Taking into account that such inhibitors are potent inductors of HSF1 and antiapoptotic HSP27 and HSP70, and that cancer cells show much greater dependence on HSF1 than their nontransformed counterparts, the ablation of the heat shock response through HSF1 inhibition is therefore an attractive strategy for anticancer therapy. 22,23

The strong expression of HSF1 and HSPs in HRS cells may be attributed to an increased demand for HSPs to stabilize over-expressed oncoproteins. Over-expression of NF-kB is a hallmark of HRS cells and we have also found abundant expression of p-AKT in most cases; HSP90 and its co-chaperone CDC37 are directly involved in the formation of active NF-kB and help also in the phosphorylation of the pro-survival protein AKT. CDC37 expression in 


\section{A. Santón et al.}

HRS cells is a surprising finding since this co-chaperone is an oncogene in itself and is overexpressed in a number of cancers. ${ }^{24}$ CDC37 mediates carcinogenesis by stabilizing the catalytic domains of oncogenic kinases within HSP90 complexes and provides a target for the design of selective inhibitors of multiple kinase cascades. 25,26

Given the essential roles that HSPs play in promoting cell proliferation and inhibiting death pathways, we studied the possible interactions of the major HSPs with components of extrinsic and intrinsic apoptotic pathways in HRS cells. Active caspases 3,8 and 9 were detected in $55.1 \%, 55.4 \%$ and $96.2 \%$ of cHL cases; however, cleaved PARP - the main product of caspase-3 proteolitic activity - was observed only in $16.1 \%$ of cases, which seemed to confirm an alteration of apoptotic pathways in HRS cells. Different frequencies of caspase-3 activation in $\mathrm{cHL}$ have been reported in the literature; our result resembles that of Bai et al (67\%) and is lower than those reported by others. 14,27 However, IHC detection of cleaved PARP was reported only in one work and, contrary to our result, strongly correlated with the expression of active caspase 3 .

The major inhibitory molecule that prevents proper caspase 3 activation in HRS cells through the intrinsic pathway is XIAP ${ }^{4}$ which was present in our series in $73.4 \%$ of cases. However, we did not find any significant association of XIAP or antiapoptotic BCL2 with lack of active caspases 3 or 9 . Strikingly, a strong direct association existed between the expression of active caspase 3 and that of HSP70 ( $\mathrm{p}=0.000)$. Elevated HSP70 does not preclude the activation of caspase 3 but prevents cleavage of PARP. 10, 28 HSP70 can rescue cells from a latter phase of apoptosis than any known survival-promoting protein and protection by HSP70 has been reported to occur in some cases downstream of caspase 3 activation and cleavage of its substrates. ${ }^{29}$ Although functional studies are indeed required, it is tempting to speculate that in HRS cells inhibition of the intrinsic apoptotic pathway may be at least partially attributed to the anti-apoptotic effect of HSP70 expression. 


\section{A. Santón et al.}

To check proper functioning of the stress-induced apoptotic pathway upstream caspase 3 activation and PARP processing, we studied the expression of active caspase 9 and also of p53 and its effector p21. Although active caspase 9 was detected in most cHL cases $(96.2 \%)$, this caspase seems not to be truly functional as suggested by activation of caspase 3 only in half of samples. The functional significance of the association between active caspase 9 and HSP40 in our series can only be speculative, but it might point to the HSP70-HSP40 system as a negative regulator of apoptosis since it is well known that HSP40 works in concert with HSP70, helping to lock in the binding of the chaperone to its protein substrate.

Although we have not directly sequenced p53, its expression in HRS cells was associated with that of $\mathrm{p} 21$, which seem to suggest that p53 is functionally active and is able to transactivate the $p 21$ target gene, what would support the presence of wild-type p53. 14,30 It could be inferred from our study that high levels of probably wild-type p53 may be stabilized by members of the HSP families as it has been described for the HSP70-HSP40 system. 31,32 This could be supported by the direct association found between HSP40 and p53. HO1 was also associated with p53 and p21; in some HO1 over-expressing cell lines, induction of p21 has been observed and may result in improved resistance to apoptotic stimuli .33, 34

Concerning the role of HSPs as prognostic markers, in our study multivariate analysis showed a final model in which advanced stage at presentation, lack of caspase 8 activation and absence of $\mathrm{HO} 1$ expression were the only independent variables with prognostic significance and associated with shorter OS. Despite the fact that in cHL constitutive expression of c-FLIP results in the inhibition of caspase 8 mediated apoptosis, ${ }^{3}$ we did not find significant association between presence of c-FLIP and lack of active caspase 8. Other mechanisms of caspase 8 inactivation like mutations, alternative splicing and epigenetic silencing have been reported; impaired function of caspase 8 is detected in a variety of cancers and can promote tumour progression as well as resistance to current treatment approaches. 35 Regarding HO1, 
A. Santón et al.

aside from its antioxidative action, it can directly affect cell viability by blocking apoptosis; this tumourigenic potential could seem contradictory to the protective effect of $\mathrm{HO} 1$ expression in our series of cHL patients. However, expression of HO1 in squamous cell carcinomas was associated with a higher sensitivity of patients to radiotherapy, whereas lack of HO1 was much more common in non-responders 36 and associated with lymph node metastasis. 37 Similarly, HO1 expression might be a useful indicator of treatment response in $\mathrm{cHL}$, although this result is only indicative given the small number of $\mathrm{HO} 1$ negative cases in our series; the clinical relevance of $\mathrm{HO} 1$ as a prognostic marker should be explored in a large cohort of patients.

In conclusion, HSF1 and major HSPs are strongly expressed in HRS cells, which highlights the potential use of HSP inhibitors as an attractive strategy to treat cHL. Although functional studies are indeed required, we confirm improper functioning of apoptotic machinery in HRS cells. The correlation between protein expression of different markers of the apoptotic pathway and relevant members of the HSP family might imply a role for HSPs in modulating apoptosis in HRS cells, mainly through the involvement of antiapoptotic HSP70-HSP40 system. HSPs could also be implied in the stabilization of possibly wild-type p53. Finally, advanced stage at presentation, absence of active caspase 8 and lack of HO1 expression have a negative impact in OS in our series of cHL patients.

\section{References}

1.- Re D, Küppers R, Diehl V. Molecular pathogenesis of Hodgkin's lymphoma. J Clin Oncol 2005; $23: 6379-6386$.

2. Hinz M, Löser P, Mathas S, Krappmann D, Dörken B, Scheidereit C. Constitutive NF-kB mantains high expression of a characteristic gene network, including CD40, CD86, and a set of antiapoptotic genes in Hodgkin/Reed-Sternberg cells. Blood 2001; 97:2798-2807. 


\section{A. Santón et al.}

3. Mathas S, Lietz, A, Anagnostopoulos I, et al. c-FLIP mediates resistance of Hodgkin/ReedSternberg cells to death receptor-induced apoptosis. J.Exp.Med 2004; 199: 1041-1052.

4. Kashkar H, Haefs C, Shin H, et al. XIAP-mediated caspase inhibition in Hodgkin's lymphoma-derived B cells. J Exp Med 2003; 198: 341-347.

5. Young JC, Agashe VR, Siegers K, Hartl FU. Pathways of chaperone-mediated protein folding in the cytosol. Nat Rev Mol Cell Biol 2004; 5: 781-791.

6. Beere HM. Death versus survival: functional interaction between the apoptotic and stressinducible heat shock protein pathways. J Clin Invest 2005, 115: 2633-2639.

7. Arya R, Mallik M, Lakhotia S. Heat shock genes - integrating cell survival and death. $J$ Biosci 2007; 32: 595-610.

8. Calderwood SK, Khaleque MA, Sawyer DB, Ciocca DR. Heat shock proteins in cancer: chaperones of tumorigenesis. Trends Biochem Sci 2006; 31: 164-172.

9. Whitesell L, Lindquist S. HSP90 and the chaperoning of cancer. Nat Rev Cancer 2005; 5: 761-772.

10. Schmitt E, Gehrmann M, Brunet M, Multhoff G, Garrido C. Intracellular and extracellular functions of heat shock proteins: repercussions in cancer therapy. J Leukoc Biol 2007; 81: 1527.

11. Hsu PL, Hsu SM. Abundance of heat shock proteins (hsp89, hsp60, and hsp27) in malignant cells of Hodgkin's disease. Cancer Res 1998; 58: 5507-5513.

12. García JF, Camacho FI, Morente M, et al. Hodgkin and Reed-Sternberg cells harbor alterations in the major tumor suppressor pathways and cell-cycle checkpoints: analyses using tissue microarrays. Blood 2003; 101: 681-689.

13. García-Cosío M, Santón A, Martín P, et al. Análisis of transcription factor Oct1, Oct2 and Bob1 in classical Hodgkin’s lymphoma. Mod Pathol 2004; 17:1531-1538. 
A. Santón et al.

14. Dukers DF, Meijer CJLM, Ten Berge RL, Vos W, Ossenkoppele GJ, Oudejans JJ. High numbers of active caspase 3-positive Reed-Sternberg cells in pretreatment biopsy specimens of patients with Hodgkin disease predict favorable clinical outcome. Blood 2002; 100: 36-42.

15. Bai M, Papoudou-Bai A, Horianopoulos N, Grepi C, Agnantis NJ, Kanavaros P. Expression of bcl2 family proteins and active caspase 3 in classical Hodgkin's lymphomas. Hum Pathol 2007; 38: 103-113.

16. Aleman BM, van den Belt-Dusebout AW, KlokmanWJ, Van't Veer MB, Bartelink H, van Leeuwen FE. Long-term cause-specific mortality of patients treated for Hodgkin's disease. $J$ Clin Oncol 2003, 21: 3431-3439.

17. Ciocca DR, Calderwood SK. Heat shock proteins in cancer: diagnostic, prognostic, predictive, and treatment implications. Cell Stress Chaperones 2005; 10: 86-103.

18. Garrido C, Ottavi P, Fromentin A, et al. HSP27 as a mediator of confluence-dependent resistance to cell death induced by anticancer drugs. Cancer Res 1997; 57: 2661-2667.

19. Brondani da Rocha A, Regner A, Grivicich I, et al. Radioresistance is associated to increased Hsp70 content in human glioblastoma cell lines. Int J Oncol 2004; 25: 777-785.

20. Georgakis GV, Li Y, Rassidakis GZ, Martinez-Valdez H, Medeiros LJ, Younes A. Inhibition of heat shock protein 90 function by 17-allylamino-17-demethoxy-geldanamycin in Hodgkin's lymphoma cells down-regulates Akt kinase, dephosphorylates extracellular signalregulated kinase, and induces cell cycle arrest and cell death. Clin Cancer Res 2006; 12: 584590.

21. Kamal A, Thao L, Sensinttafar J, et al. A high-affinity conformation of Hsp90 confers tumour selectivity on Hsp90 inhibitors. Nature 2003; 425: 407-410.

22. Zaarur N, Gabai VL, Porco JA, Calderwood S, Sherman MY. Targeting heat shock response to sensitize cancer cells to proteasome and Hsp90 inhibitors. Cancer Res 2006; 66: 1783-1791. 
A. Santón et al.

23. Dai C, Whitesell L, Rogers AB, Lindquist S. Heat shock factor 1 is a powerful multifaceted modifier of carcinogenesis. Cell 2007; 130: 1005-1018.

24. Gray PJ, Prince T, Cheng J, Stevenson MA, Calderwood SK. The oncogene Cdc37 is a molecular chaperone: targeting the kinome's favourite aunt. Nat Rev Cancer 2008; 8: 491495.

25. Gray PJ, Stevenson MA, Calderwood SK. Targeting Cdc37 inhibits multiple signaling pathways and induces growth arrest in prostate cancer cells. Cancer Res 2007; 67: 1194211950.

26. Smith JR, Clarke PA, De Billy E, Workman P. Silencing the cochaperone CDC37 destabilises kinase clients and sensitises cancer cells to HSP90 inhibitors. Oncogene 2009; 28: 157-169.

27. Montalbán C, García JF, Abraira V, et al. Influence of biologic markers on the outcome of Hodgkin's lymphoma: A study by the spanish Hodgkin's lymphoma study group. J Clin Oncol 2004; 22: 1664-1673.

28. Mosser DD, Caron AW, Bourget L, et al. The chaperone function of hsp70 is required for protection against stress-induced apoptosis. Mol Cell Biol 2000; 7146-7159.

29. Jaattela M, Wissing D, Kokholm K, Kallunki T, Egeblad M. Hsp70 exerts its antiapoptotic function downstream of caspase-3-like proteases. EMBO J 1998; 17: 6124-6134.

30. Montesinos-Rongen M, Roers A, Küppers R, Rajewsky K, HansmannML. Mutation of the p53 gene is not a typical feature of Hodgkin and Reed-Sternberg cells in Hodgkin's disease. Blood 1999; 94: 1755-1760.

31. Walerych D, Olszewski MB, Gutkowska M, Helwak A, Zylicz M, Zylicz A. Hsp70 molecular chaperones are required to support p53 tumor suppressor activity under stress conditions. Oncogene 2009; 28: 4284-4294.

32. Zylicz M, King FW, Wawrzynow A. Hsp70 interactions with the p53 tumor suppressor protein. EMBO J 2001; 20: 4634-4638. 
A. Santón et al.

33. Liu ZM, Chen GG, Ng EK, Leung WK, Sung JJ, Chung SC. Upregulation of heme oxygenase -1 and p21 confers resistance to apoptosis in human gastric cancer cells. Oncogene 2004; 23: 503-513.

34. Jockowicz A, Was H, Dulak J. Heme oxygenase-1 in tumors: is it a false friend? Antioxid Redox Signal 2007; 9: 2099-2118.

35. Fulda S. Caspase-8 in cancer biology and therapy. Cancer Letters 2009; 281: 128-133.

36. Yokoyama S, Mita S, Okabe A, Abe M, Ogawa M. Prediction of radiosensitivity in human esophageal squamous cell carcinomas with heme oxygenase-1: a clinicopathological and immunohistochemical study. Oncol Rep 2001; 8: 355-358.

37. Yanagawa T, Omura K, Harada H, et al. Heme oxygenase-1 expression predicts cervical lymph node metastasis of tongue squamous cell carcinomas. Oral Oncol 2004; 40: 21-27. 
A. Santón et al.

\section{Acknowledgements}

This work was supported by grants from the Fondo de Investigaciones Sanitarias del Instituto de Salud Carlos III (FIS 06/0442) and Fundación de Investigación Médica Mutua Madrileña (2007.0092), Spain.

The authors would like to thank Dr M. Piris and colleagues from Centro Nacional de Investigaciones Oncológicas for the design and construction of tissue microarrays.

\section{Disclosure/Duality of Interest}

The authors report no potential conflicts of interest. 
A. Santón et al.

Table 1. Antibodies used, staining conditions, positive controls and patterns of reactivity.

\begin{tabular}{|c|c|c|c|c|c|c|}
\hline Protein & Clone & Source & Titer & Pre-treatment & Positive control & $\begin{array}{l}\text { Staining } \\
\text { pattern }\end{array}$ \\
\hline HSF1 & $\mathrm{PC}$ & Cell Signaling & $1: 250$ & $\mathrm{TE}$ & GC-B cells & $\mathrm{N}$ \\
\hline HSP27 & G31 & Cell Signaling & $1: 50$ & $\mathrm{TE}$ & $\begin{array}{l}\text { Endothelial } \\
\text { cells }\end{array}$ & $\mathrm{C}$ \\
\hline HSP60 & LK1 & Lab Vision & $1: 200$ & $\mathrm{TE}$ & GC-B cells & $\mathrm{C}$ \\
\hline HSP70 ${ }^{\S}$ & $6 \mathrm{~B} 3$ & Cell Signaling & $1: 100$ & $\mathrm{TE}$ & RL & $\mathrm{C} / \mathrm{N}$ \\
\hline HSP90 & JPB24 & Novocastra & $1: 400$ & $\mathrm{TE}$ & GC-B cells & $\mathrm{C}$ \\
\hline HSP110 & $58 \mathrm{~F} 12$ & Novocastra & $1: 200$ & Citrate & GC-B cells & $\mathrm{C}, \mathrm{C} / \mathrm{N}$ \\
\hline HSP10 & $\mathrm{PC}$ & Stressgen & $1: 500$ & Citrate & GC-B cells & $\mathrm{C}$ \\
\hline HO1 & HO-1-2 & Stressgen & $1: 50$ & $\mathrm{TE}$ & RL & $\mathrm{N}$ \\
\hline HSP40 * & $\mathrm{PC}$ & Santacruz & $1: 250$ & $\mathrm{TE}$ & $\begin{array}{l}\text { Squamous } \\
\text { epithelia } \\
\text { (tonsil) }\end{array}$ & $\mathrm{C} / \mathrm{N}$ \\
\hline CDC37 & $\mathrm{PC}$ & Lab Vision & $1: 100$ & Citrate & GC-B cells & $\mathrm{C}$ \\
\hline $\begin{array}{l}\text { Cleaved } \\
\text { caspase } \\
(\text { Asp175) }\end{array}$ & $5 \mathrm{~A} 1$ & Cell Signaling & $1: 100$ & $\mathrm{TE}$ & RL & $\mathrm{N}, \mathrm{C} / \mathrm{N}$ \\
\hline $\begin{array}{ll}\text { Cleaved } & \\
\text { Caspase } & 8 \\
(\text { Asp391) } & \\
\end{array}$ & $18 \mathrm{C} 8$ & Cell Signaling & $1: 80$ & $\mathrm{TE}$ & RL & $\mathrm{N}, \mathrm{C} / \mathrm{N}$ \\
\hline $\begin{array}{l}\text { Cleaved } \\
\text { caspase } \\
(\text { Asp330) }\end{array}$ & $\mathrm{PC}$ & Cell Signaling & $1: 80$ & $\mathrm{TE}$ & GC-B cells & $\mathrm{N}, \mathrm{C} / \mathrm{N}$ \\
\hline $\begin{array}{l}\text { Cleaved- } \\
\text { PARP } \\
(\text { Asp214) }\end{array}$ & $\mathrm{PC}$ & Cell Signaling & $1: 50$ & $\mathrm{TE}$ & $\mathrm{RL}$ & $\mathrm{N}, \mathrm{C} / \mathrm{N}$ \\
\hline FLIP & NF6 & Alexis & $1: 80$ & $\mathrm{TE}$ & DLBCL & $\mathrm{C}$ \\
\hline XIAP & $2 \mathrm{~F} 1$ & MBL & $1: 50$ & $\mathrm{TE}$ & RL & $\mathrm{C}$ \\
\hline $\mathrm{P} 21$ & CP74 & Lab Vision & $1: 50$ & $\mathrm{TE}$ & $\begin{array}{l}\text { Scattered GC } \\
\text { cells }\end{array}$ & $\mathrm{N}$ \\
\hline BCL2 & 124 & Dako & $\begin{array}{l}\text { Pre- } \\
\text { diluted }\end{array}$ & $\mathrm{TE}$ & $\begin{array}{l}\text { Small } \\
\text { lymphocytes }\end{array}$ & $\mathrm{C}$ \\
\hline P53 & DO-7 & Novocastra & $1: 20$ & $\mathrm{TE}$ & $\begin{array}{l}\text { Scattered GC } \\
\text { cells }\end{array}$ & $\mathrm{N}$ \\
\hline p-AKT & Ser473 & Cell Signaling & $1: 50$ & Citrate & RL & $\mathrm{C}$ \\
\hline
\end{tabular}


A. Santón et al.

$\S$,* Immunodetection was accomplished with a peroxidase-conjugated rabbit ${ }^{\S}$ anti-rat or $*$ antigoat secondary antibody at 1/100 dilution.

Abbreviations:

PC: polyclonal; TE: Tris/EDTA 10mM/1mM, pH 9; Citrate: $10 \mathrm{mM}$ citrate buffer $\mathrm{pH}$ 6.5; GC-B cells: germinal center B cells; DLBCL: diffuse large B-cell lymphoma; RL: Reactive lymphadenitis; $\mathrm{N}$ : nuclear staining; $\mathrm{C}$ : cytoplasmic staining; $\mathrm{C} / \mathrm{N}$ : both cytoplasmic and nuclear staining. 
A. Santón et al.

Table 2. Characteristics of patients.

\begin{tabular}{|c|c|c|}
\hline Clinical characteristics & No./total & $\%$ \\
\hline \multicolumn{3}{|l|}{ Median age, years (range) } \\
\hline \multicolumn{3}{|l|}{$47(7-83)$} \\
\hline \multicolumn{3}{|l|}{ Sex } \\
\hline Males & $49 / 86$ & 57.5 \\
\hline Females & $37 / 86$ & 42.5 \\
\hline \multicolumn{3}{|l|}{ Stage } \\
\hline $\bar{I}$ & $8 / 81$ & 9.9 \\
\hline II & $36 / 81$ & 44.4 \\
\hline III & $17 / 81$ & 21 \\
\hline IV & $20 / 81$ & 24.7 \\
\hline \multicolumn{3}{|l|}{ B symptoms } \\
\hline Yes & $39 / 79$ & 49.4 \\
\hline No & $40 / 79$ & 50.6 \\
\hline \multicolumn{3}{|l|}{ IPS } \\
\hline $0-2$ & $62 / 80$ & 77.5 \\
\hline$\geq 3$ & $18 / 80$ & 22.7 \\
\hline \multicolumn{3}{|l|}{ Therapy } \\
\hline Radiotherapy & $40 / 76$ & 52.6 \\
\hline \multicolumn{3}{|l|}{ Chemotherapy } \\
\hline No* & $5 * / 76$ & 6.6 \\
\hline Adriamycin-containing & $65 / 76$ & 85.5 \\
\hline MOPP & $5 / 76$ & 6.6 \\
\hline Other & $1 / 76$ & 1.3 \\
\hline APSCT & $7 / 76$ & 9.2 \\
\hline Complete Remission & $67 / 76$ & 88.2 \\
\hline Relapse & $25 / 76$ & 32.9 \\
\hline Death & $28 / 76$ & 36.4 \\
\hline
\end{tabular}

* Two patients were treated only with excisional surgery and 3 received only radiotherapy APSCT: autologous peripheral stem-cell transplantation. 
A. Santón et al.

\section{Titles and legends to figures}

Figure 1. Immunohistochemical staining patterns of the main markers studied in our classical Hodgkin lymphoma cases (X600): (A) HSP27, (B) HSP40, (C) HSP60, (D) HSP70, (E) HSP90, (F) HSP110, (G) HO1, (H) HSF1, (I) CDC37, (J) active caspase 3, (K) active caspase 8, (L) cleaved PARP.

Figure 2. Comparison of overall survival time according to active caspase 8 expression in Hodgkin/Reed-Sternberg cells. 


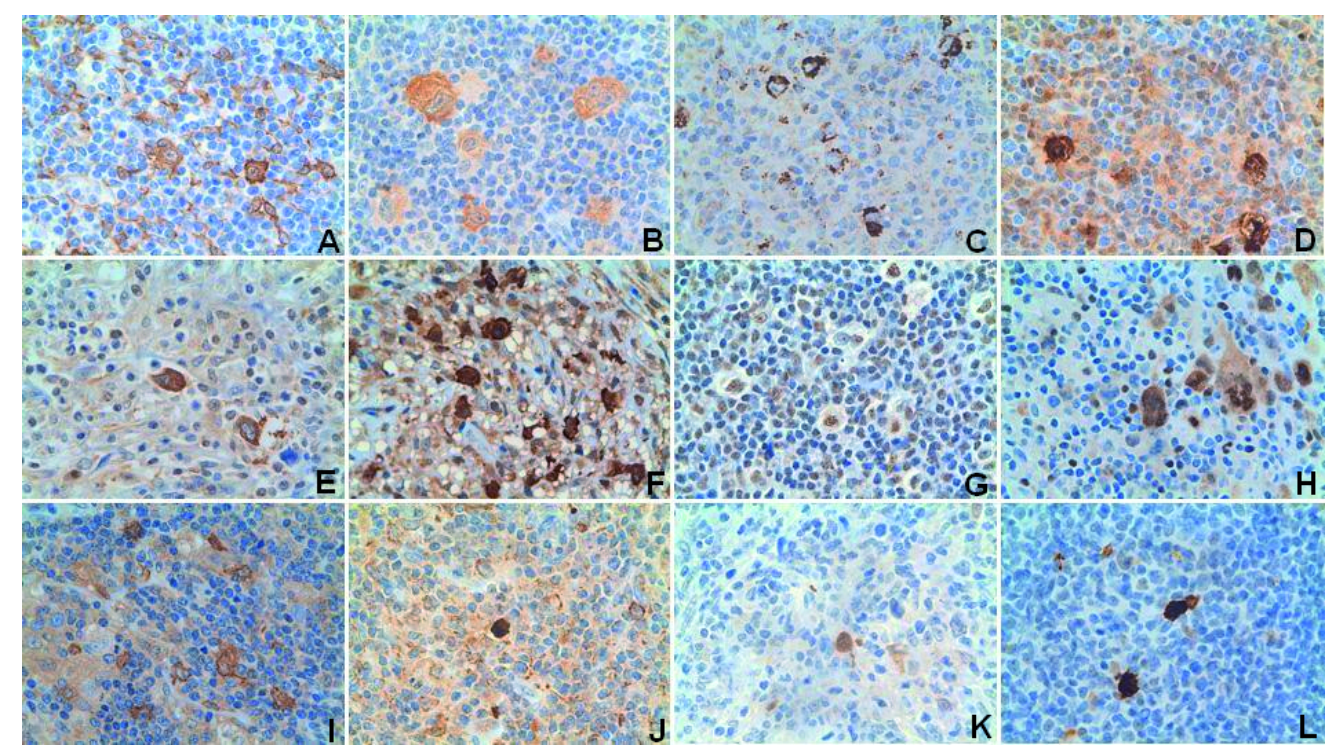

I mmunohistochemical staining patterns of the main markers studied in our classical $250 \times 140 \mathrm{~mm}(96 \times 96 \mathrm{DPI})$ 


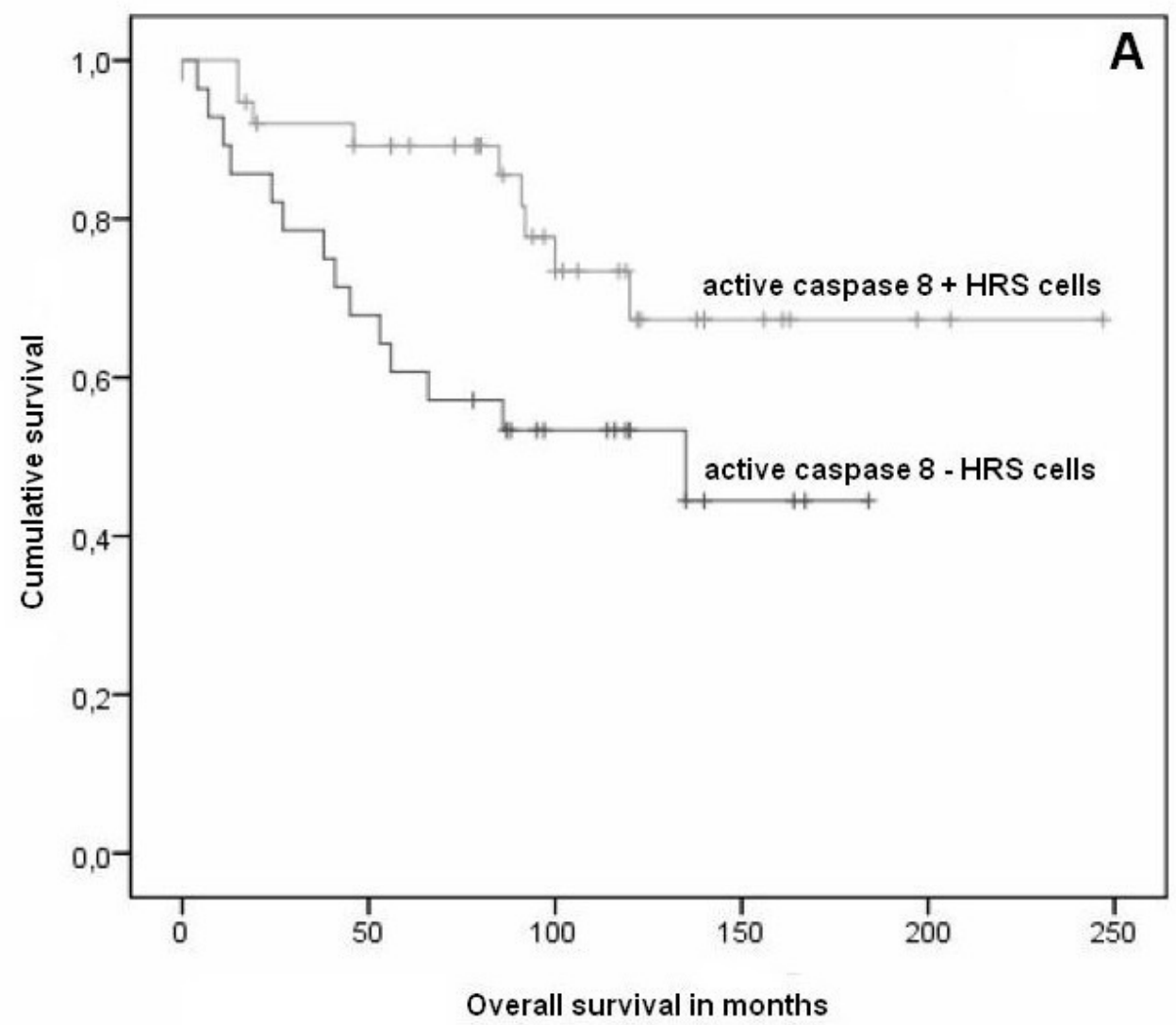

Comparison of overall survival time according to active caspase 8 expression in Hodgkin/ReedSternberg cells.

$56 \times 51 \mathrm{~mm}(300 \times 300 \mathrm{DPI})$ 